\title{
Supportive Environment at Day Care Nurseries and Children's Growth and Development
}

\author{
Eman M. Seif El-Nasr \\ Community Health Nursing, Faculty of Nursing, Cairo University, Egypt
}

\begin{abstract}
Early years represent the most important period of growth and development in the children's life, so day care nurseries must be designed and equipped to promote health of children by providing a supportive environment to explore and widen children health and skills. Aim; The study aimed to identify the effect of supportive environment provided at day care nursery on growth and development of children at rural area. Design; A descriptive correlational design was used in this study. Setting; this study was conducted at three day care nurseries at Manshiaa ELkanatr, Giza Governorate. Sample; All available children (186) and their caregivers (34) working at the day care nurseries were included in the study. Tools; Four tools were used to collect the data pertinent to the study: 1) Structured interviewing questionnaire, 2) Denver Developmental Screening Test, 3) The Home observation measurement of the environment and 4) Anthropometric tool. Results; the study results revealed that, 50\% of day care nurseries were providing supportive environment to children, a highly statistically significant negative correlation was found between numbers of children cared by caregivers and children's health. A highly statistically positive correlation was found between the sanitary environment of day care nurseries and the children's cognitive, emotional and social interaction. Conclusion: children attending at day care nursery with supportive environment had better health than those attending day care nurseries not get supportive environment. Recommendations; periodic screening for day care nursery is important to detect any health problems among children and if there is a delay in growth and development. Guidelines should be developed and disseminated to parents and caregivers for early detection of children have delay in growth and development.
\end{abstract}

Keywords: supportive environment, growth and development and day care nursery.

\section{Introduction}

Children of today are adults of tomorrow so they deserve to inherit a safe, fair and healthy environment. Supportive environment for physical, cognitive, social and emotional development in early childhood lays a good foundation for their wellbeing and success in later life [1]. Children need safe and secure environment to develop physical, social and emotional skills. If children experience unsupportive environment in which they do not feel safe and secure so children may develop patterns of behavior and negative coping strategies that increase risk of mental health difficulties in adolescence or adulthood [2].

Biological mother provide child all possible supportive environment at home. Mother and child isolated at home inevitably constitute a disadvantaged supportive and nurturing environment and that young children need not only the skilled care of experienced personnel but also the stimulation of their language, fine motor, gross motor, and psychosocial development from interaction with other children [3]. Individuals and communities must be committed to provide safe, stable and supportive environments for all children. Children detect their world through relationships with parents and other caregivers. This relationship provides a buffer against the effects of potential stressors and gain healthy brain development [4].

Supportive environment is a setting in which all children feel socially, emotionally and physically safe and valued. It includes place, equipment and materials as well as the relationships between caregivers and children. The environment should be carefully planned based on development of children. Thus, supportive environment is designed to be responsive to children's needs and provide opportunities for learning and growth in all developmental stage [5].

A day care nursery provides the child with supportive environment through cognitive, emotional, and social interaction. As well, it provides the child with care givers who are professional in child care and change of child from home to day care nursery environment is a big step toward stimulating the development of child. Moreover, at this age the child is adjusting to the outside world as well as to the family group [2]. As a result promoting safe, stable and supportive environments have a positive impact on the development of skills that help children reach their full potential [5].

The first day care nursery in Egypt was established in 1918, which signifies the Egyptian government's awareness of the day care nursery's importance. Egyptian day care nursery objectives are integrated and comprehensive child mental, physical, kinetic, emotional, social and moral care for all children, taking into consideration the individual differences in abilities, readiness and developmental levels and developing child 
language, numerical, and art skills through individual and group activities and developing ability [6]. Day care nursery objectives also include socialization and healthy life in the context of society values, principles, and preparing the child for school life in the basic education stage through graded transition from the family atmosphere to the school to be accustomed to the school life, and form human relations with teachers and classmates, and practice educational activities that suit the child interests and development rates in all fields [7].

The early childhood period is unique and characterized by key developmental stages. According to various developmental theories, development occurs across many dimensions: physiological, cognitive, social, emotional, and behavioral, and hence it is a critical period where children are vulnerable to the adverse effects of inadequate health, malnutrition, abuse, and deprivation of parental care and responsibility. It is also a period in which children learn about who they are and what they can do and create and who they will be [8].

[9] Explained that as the early years represent the most important period of growth and development in child's life, day care nurseries have been designed and equipped to provide a stimulating and child-centered supportive environment. [5] Indicated that a good supportive environment provided by day care nursery should challenge the child's imagination and creativity. It is also an attempt to acquaint children with the social world in such a way that it will add to their security and increase independence.

Child growth and development are multi-dimensional and includes cognitive-language, sensory-motor, and social-emotional domains, all of which are interdependent. The work of community health nurse in nursery includes making sure that children are safe, happy and stimulated, encouraging children's development, creating a child friendly environment, finding ways to stimulate children particularly those with special and sensory needs, supporting carers in the parenting of their children and keeping records. In addition, community health nurse supervise staff, coordinate a program of activities for children, set up a daily routine for the nursery, attend meetings, work with other professionals within and outside the nursery, support children who have been abused and promote public health and parenting [10].

Children in Egypt represent the major population category. Consequently their welfare reflects the country's welfare in the future. Children shape the future of Egypt and its way to progress and development. Children today are tomorrow's youth and leaders. Child care and preparation for future is a cultural inevitability imposed by temporary scientific and technological advancement. Social development relies on the programs, laws and institutions devoted to bringing up children since the nation's future lies in the children's future [11].

Egyptian Ministry of Social Solidarity decided to cooperate in a joint project to enhance and improve early childhood education in nurseries in some governorates all over Egypt. The Project aims at implementing several measures and activities in order to obtain fundamental mental stability, physical and social ability for the child so that he/she could grow mentally stable, having sound habit and social manners. As, nursery caregivers who are the closest communicative partners to the children had to be reached in order to raise their awareness of the importance of this early stage of learning, increase their knowledge of childhood stage capacities and to enhance their skills of teaching and communicating with children [12].

As childhood is a critical period for physical, psychological and behavioral development; periodical assessment for day care nurseries by community health nurses is needed to assist caregivers in providing safe and supportive environment for children health. The present study aims to assess the relationship of supportive environment on the growth and development of children at rural area.

The aim of the study is to assess the relationship between supportive environment and the growth and development of children at rural daycare nurseries. Three research questions were formulated: (1) what is the supportive environment provided at rural day care nurseries to children? (2) What are the growth and development of the children at rural day care nurseries? (3) What is the relationship between the supportive environment in day care nurseries and the growth and development of children?

\subsection{Research design;}

\section{Subjects and Methods}

A descriptive correlational design was used in this study. This design finds out what is happening, generate new insights, ask questions, assesses phenomena in new light, generate ideas and seeks to give an accurate profile of people, events and situations and display the relationships among variables [13].

\subsection{Research setting}

Giza governorate is divided into four directions; North, South, East and West. Rural areas are located at the North and South direction. Through using simple random sample technique, the north direction was selected then one rural area was selected randomly from the North direction. This rural area was Manshiet ELkanatr. According to [14] this area is 200 square kilometers and around 464,889 inhabitants. All day care nurseries in this area were included in this study (EL-Zohoor for boys, Shorook nursery for girls and El-model day care nursery for boys and girls). 


\subsection{Research sample}

All children enrolled in the previous day care nurseries (186) and caregivers (34) who are working in the day care nurseries were included in the study.

\subsection{Tools for data collection}

Four tools were used to collect data.

(1) Demographic structured questionnaire: this tool is divided into two sections; A- Data about the child as age and sex B- Data about caregiver's age, education, income, marital status and work experiences.

(2) Denver Developmental Screening Test (DDST-Denver II) was developed by William K. Frankenburg (1967) [15]. The test is designed to compare a given child's performance on a variety of tasks to the performance of other children of the same age group. It consists of tasks which are arranged on the test form on four sectors to screen the following areas of function: a) personal-social, getting along with people and caring for personal needs. b) Fine motor-adaptive, eye hand coordination, manipulation of small objects and problem solving. c) Language hearing, understanding and using language. d) Gross motor, sitting, walking and jumping and overall large muscles movement.

Scoring system: The scoring of DDST includes tasks corresponding to the age and to which the child be subject were counted, a zero score was given for the failed tasks. These tasks were given a score according to the percentile presented in the test paper of DDST scale. The points gained by the child were calculated as percentage from the total expected score. Children were divided according to 3 class intervals, less than $50 \%$ of the expected maximum score, $50 \%-70 \%$, and $75 \%$ or more.

(3) The Home Observation Measurement of the Environment (HOME) Inventory [16] was used to identify the supportive environment at the day care nurseries. HOME inventory has six categories to measure the supportive environment which includes; 1.Stimulation through toys and games, 2.Stimulation of academic behavior, 3. Modeling and encouraging of social interaction, 4.Language stimulation 5.Organization of the physical environment. 6 . Variety in daily stimulation.

Scoring system: the scoring of this inventory is that in each of these six categories a set of observation are to be made at day care nurseries by researcher and the answer is either yes if the behavior is observed or no if not.

(4) Anthropometric measurement: were used to measure children's weight, height and head circumferences, using weighing scale and non-stretchable tape measure.

\subsection{Ethical consideration}

An approval was obtained from the day care nursery directors, parents of children and caregivers. Each participant was informed about the purpose of the study and its importance. The researcher emphasized that, participation in the study was entirely voluntary. Anonymity and confidentiality were also assured through coding the data. An informed verbal consent was obtained from parents of the children and they were informed that they can withdraw at any time.

\subsection{Pilot Study}

A total of $10 \%$ of the children were included in the pilot study in order to assess the feasibility and clarity of the tools and determine the needed time to complete the study tools. Based on its results minor changes were carried out and these children were included in the study.

\subsection{Procedure}

Permission was obtained from the day care nursery directors, parents of children and caregivers who agreed to participate in the study. Data collected through a period of 6 months from October 2015 to the end of March 2016, two days/week from 9.00 a.m. to 12.00 p.m.

The researcher assessed the children's growth and development, through their anthropometric measurements. Measurements of each child "weight, height, head circumference" were done, then calculation by percentile according to age was done. The development of child was monitored by using of DDST- Denver II scale. Before administrating the test, the child was given the chance to be acquainted with the researcher to get his or her cooperation during the test. On checking the interaction between the caregiver and the child, the caregivers were spontaneously observed during the interaction with the child through using the HOME inventory. As well, the HOME inventory was used to identify certain aspects of quality and quantity of the social, emotional, and cognitive supportive and sanitary environment available to the child at the day care nurseries. 


\subsection{Statistical Analysis}

Data were analyzed using Statistical Package for Social Science (SPSS windows) version 20. Numerical data were expressed as mean $\pm \mathrm{SD}$, and range. Relations between different numerical variables were tested using Pearson correlation. Probability (p-value) less than 0.05 was considered significant and less than 0.001 was considered as highly significant.

\section{Results}

The study results will be presented in four parts: part 1: Characteristics of the children and caregivers, part 2: Growth and development of children, part 3: Supportive environment at day care nurseries and part 4: Correlation between variables.

Results revealed that, the age of children ranged between 12 months to 66 months with a mean of $28.1 \pm 18.2$ months. Infants accounted for $26.5 \%$ and preschoolers were $73.5 \%$. Girls represented $54.3 \%$ compared to $45.7 \%$ of boys.

Regarding caregiver's characteristics, $72.3 \%$ of caregivers aged from 25 years to less than 35 years, where as $17.7 \%$ aged 45 years or more. Regarding caregiver's education, $53.8 \%$ of them got commercial diploma and only $2.9 \%$ had higher education, only $5.9 \%$ had work experience more than 10 years with a mean experience of $6.17 \pm 4.9$ years. As for income $82.4 \%$ of caregivers had a monthly income of 300-350 Egyptian pounds. Being single accounted for $67.7 \%$ and $32.3 \%$ of them were married. In relation to caregiver's working hours, $38.2 \%$ were working $6-9$ hours per day, and $61.8 \%$ of them were working for more than 9 hours daily. More than half of caregivers (58.8\%) were giving care to 10 children or more, while $41.2 \%$ were giving care to 3-4 children.

The results of the study revealed that, more than half ( $55 \%$ ) of children were in the 25 th -74 th percentile accounting for $63.9 \%$ weight, $69.4 \%$ height and $69.3 \%$ head circumference. Only $14.7 \%$ were in the percentile 75th. Studying the anthropometric measurements in relation to sex, results showed that, $48.5 \%$ of the girls were less than 50 percentile (64.4\% for weight, $46.5 \%$ for height and $52.6 \%$ for head circumference). Regarding boys, $37.6 \%$ for weight, $61.2 \%$ for height and $81.1 \%$ for head circumference were in the $50-74$ th percentile.

Regarding development of children, the study revealed that, the higher percentage of the 4 aspects of development were in the 50-74 percentile accounting for $46.6 \%$ ( psychosocial), $60.1 \%$ (fine motor), $50.6 \%$ (language) and $60.4 \%$ (gross motor). The percentile less than 50 represented $28 \%$ (psychosocial), $21.1 \%$ (fine motor) and $18.9 \%$ (language) and $14.4 \%$ (gross motor). Studying children development in relation to sex indicated that, higher percentage among boys and girls were in the 50th - 74th percentile as boys got $48.2 \%$ for psychosocial, $54.1 \%$ for fine motor, $67.1 \%$ for language, and $54.1 \%$ for gross motor compared to $45.5 \%$, $65.3 \%, 66.3 \%$ and $44.6 \%$ in girls respectively.

Results of this study revealed that $56.7 \%$ of children got moderate social interaction from caregivers. Also, $35.9 \%$ of the children received poor social interaction. In Relation to the social interaction and gender results indicated that, $52.5 \%$ of girls got poor social interaction compared to $48.2 \%$ of boys. Good social interaction was received by only $2 \%$ of girls and $35.3 \%$ of boys.

Regarding emotional support, $19.4 \%$ of the children got poor emotional support while $37.6 \%$ of them got good emotional support. As for the emotional support and children's sex, results clarified that, the majority of boys (82.4\%) got good emotional support. As regard to the cognitive support, the study indicated that, $62.4 \%$ of the children got good cognitive support and when relating to sex; the majority of boys (81.3\%) and none of girls good cognitive support. On checking the sanitation at day care nurseries, it was found that, $62 \%$ of children were living in day care nurseries with moderate sanitary environment, whereas $38 \%$ of them were living in good sanitary day care nurseries.

Regarding growth of children, the study revealed highly statistically significant differences, between children's sex and weight, height, and head circumference ( $\mathrm{t}=5.34,5.96$ and 6.46 respectively $\mathrm{p}=<0.0001)$. The study showed a statistically significant negative correlation between number of children cared for by caregivers and children's weight $(r=-0.355, p=0.01)$, height $(r=-0.269, p=0.01)$ and head circumference $(r=-$ $0.218, \mathrm{p}=0.01$ ).

Regarding children's development, the study showed highly statistically significant differences between sex and children's psychosocial development $\quad(\mathrm{t}=6.23, \mathrm{p}=<0.0001)$, fine motor $(\mathrm{t}=5.23, \mathrm{p}=<$ $0.0001)$, language $(\mathrm{t}=6.22, \quad \mathrm{p}=<0.0001)$ and gross motor $(\mathrm{t}=6.67, \mathrm{p}=<0.0001)$. In addition, statistically significant negative correlations were found between number of children cared for by caregivers and their developmental aspects as psychosocial development $(\mathrm{r}=-0.311, \mathrm{p}=0.05)$, fine motor $(\mathrm{r}=-0.232, \mathrm{p}=0.01)$, language development $(\mathrm{r}=-0.437, \mathrm{p}=0.05)$ and gross motor development $(\mathrm{r}=-0.372, \mathrm{p}=0.01)$.

Regarding characteristics of caregivers and children development (Table 1), this study revealed a statistically significant negative correlations between caregiver's age and work experience and children's 
growth and development ( $\mathrm{P}=<0.0001)$. Table (1) shows statistically significant correlations between caregiver's working hours and children's weight, height and language $(\mathrm{p}=<0.0001)$. Table $(2)$ reveals that, education had a highly statistically significant relation with children's anthropometric measurements $(\mathrm{p}=<0.0001)$. Also there were statistically significant differences between caregiver's marital status and children's weight $(\mathrm{P}=0.05)$, head circumference $(\mathrm{P}=0.02)$, language $(\mathrm{P}=0.03)$ and gross motor $(\mathrm{P}=0.01)$.

The study results revealed statistically significant relations between caregiver's social interaction and their age $(r=0.319, p=0.01)$, work experience $\quad(r=0.362, p=0.01)$ and working hours $(r=0.183, p=0.05)$. There was a highly significant relation between social interaction and education of the caregivers $\quad(\mathrm{F}=$ $20.36, \mathrm{P}=<0.0001)$. No significant difference was found between social interaction and marital status or income of caregivers. But, highly significant difference $(\mathrm{p}=<0.0001)$ was found between education of caregivers and environmental support provided at day care nurseries.

In addition, the study denoted positive correlations between social interaction, cognitive support, emotional support and sanitary environment with the growth and development of children (Table 3). Table (4) indicates positive correlations between social interaction and growth and development of boys and girls. In addition sanitary environment was positively correlated with weight of boys and girls. Table (5) reveals positive correlations between cognitive support with weight of boys and girls.

Regarding the relation of number of children cared by caregivers to the supportive environment provided at day care nurseries the results showed highly significant negative correlations with social interaction $(\mathrm{r}=-0.371 \mathrm{p}=<0.00001)$, emotional support $(\mathrm{r}=-0.840, \mathrm{p}=<0.00001)$, cognitive support $(\mathrm{r}=-0.826, \quad \mathrm{p}=<$ $0.00001)$ and sanitary environment $(\mathrm{r}=-0.845, \mathrm{p}=<0.00001)$.

Table (1).Correlation between children's growth and development and caregiver's characteristics

\begin{tabular}{|c|c|c|c|c|c|c|c|c|}
\hline \multirow[t]{2}{*}{$\begin{array}{l}\text { Growth and } \\
\text { development }\end{array}$} & \multicolumn{2}{|c|}{ Age } & \multicolumn{2}{|c|}{$\begin{array}{c}\text { Work } \\
\text { Experience }\end{array}$} & \multicolumn{2}{|c|}{ Income } & \multicolumn{2}{|c|}{ Working Hours } \\
\hline & $\mathrm{R}$ & $\mathrm{p}$ & $\mathrm{R}$ & $\mathrm{p}$ & $\mathrm{R}$ & $\mathrm{p}$ & $\mathrm{R}$ & $\mathrm{p}$ \\
\hline Weight & -0.36 & $<0.0001$ & -0.35 & $<0.0001$ & 0.394 & $<0.0001$ & 0.143 & 0.05 \\
\hline Height & -0.37 & $<0.0001$ & -0.29 & $<0.000$ & -0.009 & 0.9 & 0.146 & 0.04 \\
\hline Psychosocial & -0.36 & $<0.0001$ & -0.43 & $<0.0001$ & 0.126 & 0.08 & -0.027 & 0.7 \\
\hline Fine motor & -0.35 & $<0.0001$ & -0.33 & $<0.0001$ & -0.006 & 0.9 & 0.013 & 0.8 \\
\hline Language & -0.33 & $<0.0001$ & -0.36 & $<0.0001$ & 0.959 & $<0.0001$ & 0.185 & 0.01 \\
\hline Gross motor & -0.43 & $<0.0001$ & -0.32 & $<0.0001$ & 0.000 & 1 & 0.121 & 0.09 \\
\hline
\end{tabular}

Table (2).Relation between caregivers' education and marital status and children growth and development

\begin{tabular}{|l|c|c|c|c|}
\hline \multicolumn{1}{|c|}{ Growth and development } & $\begin{array}{c}\text { Education } \\
\text { (t-test) }\end{array}$ & $\mathrm{p}$ & Marital status (t-test) & $\mathrm{p}$ \\
\hline Weight & 18.43 & $<0.0001$ & 1.69 & 0.05 \\
Height & 17.96 & $<0.0001$ & 1.54 & 0.06 \\
Head circumference & 14.01 & $<0.0001$ & 2.17 & 0.02 \\
Psychosocial & 10.76 & $<0.0001$ & -0.40 & 0.34 \\
Fine motor & 06.68 & $<0.0001$ & 0.80 & 0.00 \\
Language & 22.12 & $<0.0001$ & 1.96 & 0.03 \\
Gross motor & 23.89 & $<0.0001$ & 2.26 & 0.01 \\
\hline
\end{tabular}

Table (3).Correlation between Home Observation for Measurement of the Environment and children growth and development

\begin{tabular}{|l|c|c|c|c|c|c|c|c|}
\hline \multirow{2}{*}{$\begin{array}{c}\text { Growth and } \\
\text { development }\end{array}$} & \multicolumn{2}{|c|}{ Social interaction } & \multicolumn{2}{c|}{$\begin{array}{c}\text { Cognitive } \\
\text { support }\end{array}$} & \multicolumn{2}{c|}{$\begin{array}{c}\text { Emotional } \\
\text { support }\end{array}$} & \multicolumn{2}{c|}{ Sanitary environment } \\
\cline { 2 - 7 } & $\mathrm{R}$ & $\mathrm{p}$ & $\mathrm{R}$ & $\mathrm{p}$ & $\mathrm{R}$ & $\mathrm{p}$ & $\mathrm{R}$ & $\mathrm{p}$ \\
\hline Weight & 0.76 & $<0.0001$ & 0.35 & $<0.0001$ & 0.35 & $<0.0001$ & 0.35 & $<0.0001$ \\
Height & 0.63 & $<0.0001$ & 0.33 & $<0.0001$ & 0.32 & $<0.0001$ & 0.30 & 0.0000 \\
Psychosocial & 0.82 & $<0.0001$ & 0.28 & 0.0001 & 0.29 & 0.000 & 0.29 \\
Fine motor & 0.53 & $<0.0001$ & 0.24 & 0.009 & 0.25 & 0.0005 & 0.26 \\
Language & 0.68 & $<0.0001$ & 0.39 & $<0.0001$ & 0.42 & $<0.0001$ & 0.42 & $<0.0000$ \\
Gross motor & 0.65 & $<0.0001$ & 0.42 & $<0.0001$ & 0.42 & $<0.0001$ & 0.42 & $<0.0001$ \\
\hline
\end{tabular}


Table (4).Correlation between social interaction, sanitary environment and growth and development of boys and girls

\begin{tabular}{|c|c|c|c|c|c|c|c|c|}
\hline HOME & \multicolumn{4}{|c|}{ Social interaction } & \multicolumn{4}{|c|}{ Sanitary environment } \\
\hline \multirow{2}{*}{$\begin{array}{l}\text { Growth and } \\
\text { development }\end{array}$} & \multicolumn{2}{|c|}{ Boys (85) } & \multicolumn{2}{|c|}{ Girls (101) } & \multicolumn{2}{|c|}{ Boys (85) } & \multicolumn{2}{|c|}{ Girls (101) } \\
\hline & $\mathrm{R}$ & $\mathrm{p}$ & $\mathrm{R}$ & $\mathrm{p}$ & $\mathrm{R}$ & $\mathrm{p}$ & $\mathrm{R}$ & $\mathrm{p}$ \\
\hline Weight & 0.714 & $<0.0001$ & 0.472 & $<0.0001$ & 0.179 & 0.01 & 0.881 & 0.001 \\
\hline Height & 0.632 & $<0.0001$ & 0.498 & $<0.0001$ & 0.061 & 0.41 & 0.134 & 0.18 \\
\hline Psychosocial & 0.771 & $<0.0001$ & 0.791 & $<0.0001$ & -0.101 & 0.17 & 0.127 & 0.21 \\
\hline Fine motor & 0.473 & $<0.0001$ & 0.426 & $<0.0001$ & -0.083 & 0.26 & 0.272 & 0.05 \\
\hline Language & 0.562 & $<0.0001$ & 0.656 & $<0.0001$ & 0.250 & 0.05 & 0.131 & 0.191 \\
\hline Gross motor & 0.479 & $<0.0001$ & 0.645 & $<0.0001$ & 0.108 & 0.14 & 0.101 & 0.31 \\
\hline
\end{tabular}

Table (5): Correlation between cognitive support and emotional support with growth and development of boys and girls

\begin{tabular}{|l|c|c|c|c|c|c|c|c|}
\hline \multirow{2}{*}{ HOME } & \multicolumn{4}{c|}{ Cognitive support } & \multicolumn{3}{c|}{ Emotional support } \\
\hline $\begin{array}{l}\text { Growth and } \\
\text { development }\end{array}$ & \multicolumn{2}{|c|}{ Boys (85) } & \multicolumn{2}{c|}{ Girls (101) } & \multicolumn{2}{c|}{ Boys (85) } & \multicolumn{2}{c|}{ Girls (101) } \\
\cline { 2 - 9 } & $\mathrm{R}$ & $\mathrm{p}$ & $\mathrm{R}$ & $\mathrm{p}$ & $\mathrm{R}$ & $\mathrm{p}$ & $\mathrm{R}$ & $\mathrm{p}$ \\
\hline Weight & 0.204 & 0.005 & -0.311 & 0.001 & 0.181 & 0.09 & -0.143 & 0.15 \\
Height & 0.059 & 0.59 & -0.306 & 0.001 & 0.059 & 0.59 & -0.166 & 0.09 \\
Psychosocial & -0.093 & 0.39 & -0.172 & 0.08 & -0.142 & 0.19 & 0.092 & 0.36 \\
Fine motor & -0.095 & 0.38 & 0.057 & 0.57 & -0.136 & 0.21 & 0.217 & 0.02 \\
Language & 0.277 & 0.01 & -0.131 & 0.19 & 0.165 & 0.13 & 0.041 & 0.68 \\
Gross motor & 0.119 & 0.27 & -0.188 & 0.06 & 0.094 & 0.39 & 0.006 & 0.95 \\
\hline
\end{tabular}

\section{Discussion}

Supportive environment at day care nursery promotes the health of the young children. The growth and development of children affects not only their responsiveness in the developmental process but the responsiveness of the surrounding environment and others to them as well. Children in a supportive environment promote their social, emotional and cognitive functions and at the same time under the supervision of well trained personnel so their understanding of themselves and others develop normally [5].

The present study revealed that, all examined children were within the normal weight, height and head circumference for their ages. [17] Illustrated that when a young child is growing along his or her expected curve on standard growth chart, it provides some degree of objective evidence that both diet and supportive environment provided to children in the form of emotional, social, cognitive support and sanitary environment are adequate for promoting the growth and development of young children

Comparing the growth of children to their sex, it was found that higher percentages of girls than boys fell in the percentile less than 50 for height, weight and head circumferences. When the development of children was compared to sex, the current study showed that, girls' were less than boys in all sectors of their development. [18] Revealed that differences in growth and development between boys and girls are well known and have been reported in most studies as it is affected by a combination of genetic and environmental factors.

Concerning the characteristics of caregivers, in the present study showed a significant relations between education of caregivers and growth and development of children. The same was found by [2] where caregiver's education was expected to enhance and promote children's development especially psychosocial development. Also, [9] assured that education level of caregiver is positively correlated with the child's development. This could be related that educated caregivers took better care of children and acknowledged the importance of balanced diet, cleanliness and hygiene.

Results revealed that, age and work experience of caregivers were negatively correlated with children's growth of children. These findings may be attributed to the caregiver's lack of energy and interest due to their older age and most of these nurseries operate on a very tight budget. Also there were negative correlation between children psychosocial development and age of caregivers. [3] Clarified that nursery is a time for learning more appropriate ways of interacting with others. Many children are also developing a sense of humour and playing with language. They begin to take name-calling, teasing, and criticism seriously, and get opportunity to learn about the importance of understanding, accepting, and accommodating differences as part of their social and emotional development. Results of this study could be related to that older caregivers were not able to tolerate children exploration of their own feelings, identities, and social relationships with others that arising noise from these children.

Regarding growth and development of children, there is positive correlation between child's growth and development and supportive environment, this result was supported by [1] who found that the type and quality of environment support to children promotes and foster child psychosocial development. Children's growth and development are continually influenced by their environment. Growth is enhanced by love, good 
nutrition, shelter, medical care, and protection from harm. New experiences and planned challenges foster intellectual development, while social interaction and communication skills promote psychological development. [3] Revealed that, deprivation from stimulated environment and positive caregivers' child interaction, produced evidence of damage to children's growth and development.

A highly statistically significant positive correlation was found between the children's growth and development and their social interaction. [9] stated that one of supportive environmental characteristics at day care nursery is to be associated with favorable developmental outcomes because of the opportunities for variety of daily interaction and stimulation of children.

[1] Interpreted these because children spend the majority of their waking hours in day care nursery. [3] also revealed that supportive environment provided by day care nursery include a health physical building, positive social interaction between caregivers and children, and cognitive interaction in the form of providing simple educational material to those children, as well as emotional support.

\section{Conclusion}

Children who attend at day care nurseries with supportive environment had better growth and development than those attending at day care nurseries without supportive environment.

\section{Recommendation}

Based on the findings of the present research, the following recommendations are suggested: Periodic screening for children in day care nursery is needed to detect any deviation from the normal growth and development.Training and supervision of caregivers about characteristic of supportive environment at day care nursery. Developing guidelines to caregivers about supportive environment of day care nursery.Further researches are required on a larger sample of day care nursery to assess the impact of supportive environment on growth and development of children.

\section{References}

[1] Kamat, D. \& Fischer, P. (2015): Global Child Health, 2nd Edition. American Academy of Pediatrics.

[2] Page, J. Clare, A and Nutbrown, C. (2013): Working with Babies and Children. California. SAGE Publications.

[3] Rudolf, M. Levene, M. (2010): Paediatrics and Child Health, 2nd Edition, Wiley-Blackwell.

[4] Muir, J. Sidey, A. (2010): Textbook of Community Children's Nursing. London, Bailliere Tindall.

[5] Moore, R. \& Cosco, N., (2014): Growing up Green: Naturalization as a Health Promotion Strategy in Early Childhood Outdoor Learning Environments. Children, Youth and Environment; Vol. 24, No.2.

[6] Abdel-Rahman, A, S, (2002): Assessment of the health of preschool children at nursery school. Thesis , Faculty of Medicine, Cairo University.

[7] Education for All National Review (2014): National Center for Education, Research and Development. Egypt.

[8] Faour, B. and Suwaigh, S. (2010): Early Childhood in the Arab Countries Regional Report: Status and Challenges. United Nations Educational, Scientific and Cultural Organization (UNESCO).

[9] Eveleth, P. (2015): Maternal and Child Health around the World, Growth and development of the infant and young child. Springer, pp 137-146.

[10] Hunt, R (2009): Introduction to Community- based Nursing. 4th edition, Lippincott Williams \& Wilkins.

[11] Hassan, F. (2013): Preschool Child Development in Egypt. Suez Canal University Medical Journal. Vol. 16 (1), P 1-10.

[12] United Nations Educational, Scientific and Cultural Organization, (UNESCO). (2011): Early Childhood Care and Education (ECCE). International Bureau of Education, Egypt. Country Profile Prepared for the Education for All Global Monitoring Report. Geneva.

[13] Nandhini \& Rangarjan. (2013): A Playbook for Research Methods: Integrating Conceptual frameworks and Project Management. Available at: http//www.open library.com.

[14] The Ministry of Administrative Development (2014): General Directorate for Information and Documentation, Electronic Gate at Cairo Governorate.

[15] Eratay E, Bayoglu B, Anlar B. (2015): Preschool Developmental Screening with Denver II Test in Semi-Urban Areas. J Pediatr Child Care; $1(2): 4$

[16] Caldwell, B. M., \& Bradley, R. H. (2003): Home Observation for Measurement of the Environment: Administration Manual. Tempe, AZ: Family \& Human Dynamics Research Institute, Arizona State University.

[17] Potts , N. \& Mandleco, B. (2012): Pediatric Nursing, Caring for Children and their Families. 3rd. USA.

[18] El Mouzan, M,I, Al Herbish, A,S, Al Salloum, A,A, Foster, p,J, Al Omar, A,A, Qurachi, M,M and Kecojevic, T. (2010): Pattern of Sex Differences in Growth of Saudi Children and Adolescents . GENDER MEDICINE/VOL. 7, NO. 1 